REVIEWS

\title{
Getting underneath IPEC competencies: Core Competency 4: Teams and teamwork
}

\author{
Joann C. Harper* \\ Department of Community Health, School of Health and Human Services, National University, San Diego, CA, United States
}

Received: July 30, 2018

DOI: $10.5430 /$ jnep.v9n3p56
Accepted: October 21, 2018

Online Published: November 20, 2018

\begin{abstract}
The Interprofessional Education Collaborative (IPEC) formed in 2009 provided significant guidance to advance interprofessional collaboration in its publication of the IPEC competencies in 2011, which described Four Domains and associated competencies to address interprofessional education and practice. Its updated publication in 2016 included public health and the care of populations and clarified its intent that interprofessional collaboration is the overarching theme of the now renamed 4 Core Domains to 4 Core Competencies. The article examines the literature that correlates with the sub competency statements represented within Core Competency 4: Teams and Teamwork (TT) to identify the underpinnings that support their fulfillment. The TT core statement is broad: "Apply relationship-building values and the principles of team dynamics to perform effectively in different team roles...". There is also considerable overlap between the sub-competency statements. Though the existing literature describes structural characteristics and behavioral elements of good functioning teams, the repertoire is not collectively accessible and assimilated into a whole, but is fragmented, embedded in multiple sources. The article integrates and assembles the qualities of teams and team-members likely to be successful while getting underneath the competency statements to identify the mechanisms and dispositions that drive those competencies. The exploration begins with the structural components of teams and then proceeds to key attributes of teams and team members. The article provides a nexus to correlate IPEC's TT's sub-competencies to yield favorable team functioning from which academic institutions, and health care professionals might enrich their knowledge about what works.
\end{abstract}

Key Words: The Interprofessional Education Collaborative (IPEC), Teams, Teamwork, Interprofessional education, Interprofessional practice

\section{INTRODUCTION}

In 2011 IPEC established a framework to describe what is essential to collaborative practice within " 4 " Competency Domains and laid the groundwork for a common language to reach competency thresholds among health care professions. The development and publication of interprofessional collaborative practice competencies begun by the Canadian Interprofessional Health Collaborative (CHIC) in 2010 and subsequently the Interprofessional Education Collaborative (IPEC) in 2011, built upon the work of Barr, CHIC, et al. to catapult an understanding of elements required for health care professions. ${ }^{[1-7]}$ In 2016, IPEC updated its stance by explaining that collaboration was the overarching theme of the domains depicted in its 2011 publication and renamed each of the 4 domains as 4 Core Competencies. ${ }^{[8]}$ The thread of these overlapping IPEC cores depict the goals of teams and teamwork, delineated as Core Competency 4, however each Core Competency is interwoven with the other.

Core Competency 4 integrates the other three IPEC core com-

*Correspondence: Joann C. Harper; Email: jharper@nu.edu; Address: Department of Community Health, School of Health and Human Services, National University, San Diego, CA, United States. 
petencies to actuate positive team functioning and outcomes. For instance, without a clear understanding of the role values and ethics play for interprofessional practice in Core Competency $1(\mathrm{C} 1)$, Values and Ethics, the team is challenged to operate within shared principles and doctrines. ${ }^{\left[{ }^{[8}\right.}$ Without working knowledge of how the scope of practice and its legal parameters function within each profession to create fixed and overlapping boundaries in Core Competency 2 (C2), Roles and Responsibilities, we may not grasp what affects individual team members' perspective in decisive ways. And, without the training and insight about the profound effects of both positive and negative dialogue of Interprofessional Communication, Core Competency (C3), we miss opportunities to steady or enhance team performance. ${ }^{[8]}$

Table 1 lists the components of Core Competency 4. ${ }^{[8]}$ Component competencies, such as TT1, TT5, TT6, and TT8, reflect principles of team development and teamwork that are not exclusive to healthcare, but to all teams. These competencies draw from several disciplines that include psychological constructs coalescing with principles outlined in C3: Interprofessional Communication. Competencies. TT2 and TT7 are guided by C1: Values and Ethics, that should be incorporated into teams at ground zero to clarify the beliefs and behaviors within which the team will function and hold themselves accountable. C2: Roles and Responsibilities, are reflected in components $\mathrm{T} 3$ and $\mathrm{T} 4$ that describe how the team applies its collective understanding of the expertise of individual disciplines; yet, makes space for what we may not know about the scope and limitations of those disciplines. Finally, Sub-competencies TT9, TT10 and TT11 may integrate contemporaneous knowledge through experiential learning and quality approaches that enlighten us on methods that demonstrate the capacity to improve the team's functioning.

The overlap in the IPEC statements for Core 4 TT makes it impractical, if not incorrect, to isolate each statement and create exclusive categories for each. For instance, TT1 states "Describe the process of team development..." (p. 14) and TT10 states: "Use available evidence to inform effective teamwork..." (p. 14). ${ }^{[8]}$ Both are intertwined in the breadth of the literature review, but there are others for which there are particular relevance evidenced by the literature and these are highlighted throughout the article. With exception, TT2: "Develop consensus on the ethical principles..." (IPEC, 2016; p. 14) is directly encompassed in Core Competency 1: Values and Ethics and while it is foundational to any team, it is omitted as it is better represented in the scope of that Core.

Table 1. Core Competency 4: Teams and teamwork

\begin{tabular}{|l|l|}
\hline \multicolumn{2}{|l}{$\begin{array}{l}\text { Apply relationship-building values and the principles of team dynamics to perform effectively in different team roles to plan, deliver, and evaluate } \\
\text { patient/population-centered care and population health programs and policies that are safe, timely, efficient, effective, and equitable. }\end{array}$} \\
\hline TT1 & Describe the process of team development and the roles and practices of effective teams. \\
\hline TT2 & Develop consensus on the ethical principles to guide all aspects of team work. \\
\hline TT3 & Engage health and other professionals in shared patient-centered and population-focused problem-solving. \\
\hline TT4 & $\begin{array}{l}\text { Integrate the knowledge and experience of health and other professions to inform health and care decisions, while respecting patient and } \\
\text { community values and priorities/preferences for care. }\end{array}$ \\
\hline TT5 & Apply leadership practices that support collaborative practice and team effectiveness. \\
\hline TT6 & $\begin{array}{l}\text { Engage self and others to constructively manage disagreements about values, roles, goals, and actions that arise among health and other } \\
\text { professionals and with patients, families, and community members. }\end{array}$ \\
\hline TT7 & Share accountability with other professions, patients, and communities for outcomes relevant to prevention and health care. \\
\hline TT8 & Reflect on individual and team performance for individual, as well as team, performance improvement. \\
\hline TT9 & Use process improvement to increase effectiveness of interprofessional teamwork and team-based services, programs, and policies. \\
\hline TT10 & Use available evidence to inform effective teamwork and team-based practices. \\
\hline TT11 & Perform effectively on teams and in different team roles in a variety of settings. \\
\hline
\end{tabular}

Note. The 2016 updates to the competencies and sub-competencies appear in bold.

\section{Literature REVIEW}

While the IOM and other bodies recognized and spurred interprofessional education and practice in healthcare through several decades, ${ }^{[4-7,9]}$ industry and business spawned the use of cross-functional teams (CFTs) as a vehicle for resolving organizational problems, reaching economic goals, and improving organizational performance. ${ }^{[10-12]}$ Other influences converged for a similar theme. Efforts were intensified by recognizing high reliability teams (HRT's) as

Published by Sciedu Press special functioning teams that required explicit orchestration for high hazard circumstances within organizations, such as nuclear power plants, air traffic control systems, the military, and space shuttles. HRT's function in environments where the consequences of errors are intolerable and defy experimentation, yet exist within shifting and complex processes. ${ }^{[13-15]}$ At the same time, meeting customer demand and reducing manufacturing errors gave way to process improvement schemes to enhance customer satisfaction and 
address costly waste associated with production, operational errors, and inefficiencies. ${ }^{[16,17]}$ These confluences have resulted in a thrust for quality through the use of organizational teams, and a renewed interest in understanding individual, team, and organizational behavior. It is not surprising then, that the literature identifies sources from varied professional arenas that describe teams and how they might function best.

\subsection{Structural components: Teams and models}

The structure of teams may be referred to as the maintenance of norms and interaction patterns within teams. ${ }^{[18]}$ Structure here assumes that the leadership of an organization fully sponsors and champions the teams designed within it and provides the resources needed for the team's success. Structure may be a precursor to a team's success. Team composition and context imposed by the organization are pre-determinants of team effectiveness. Multiple models have been described, but many share common elements, and are not distinctly different. Two models are represented, each of which serves a different purpose. Model One depicts components and mechanisms at work that are constants through the life of the team and is often applied in clinical settings. Model Two presents a linear progression of team activities, outlining the steps and tasks within each stage of the team's lifecycle. Its structure is often observable in quality improvement approaches. Particularly, Model One continues to be a significant contributor to TeamSTEPPS $\mathrm{R}$ developed by the Agency of Healthcare Research and Quality (AHRQ). ${ }^{18-23]}$ Each has a sustainable design with only minor edits to subsequent iterations and neither has been constructively replaced over time.

\subsubsection{Model one}

First introduced by Salas and colleagues ${ }^{[21]}$ and reintroduced in $2009,{ }^{[20]}$ these authors examined teams and their requirements to capture a parsimonious model, applicable to a broad range of teams and contexts. They called it the Big Five Model of Teamwork and highlight five core components: team leadership, adaptability, mutual performance monitoring, backup behavior, and team orientation. Each of these is mitigated by three coordinating mechanisms: shared mental models, closed-loop communication, and mutual trust. Figure 1 depicts the model.

Model One core components. Team leadership is differentiated between functional and shared. Functional leadership, often through hierarchical structures, solves social problems by the search and use of information for problem-solving and the management of personnel and material resources. ${ }^{[20]}$ Though functional team leadership is well known for the expertise employed for problem-solving, shared leadership according to Burke, Fiore and Salas is "the transference of the leadership function among team members to take advantage of member strengths (e.g., knowledge, skills, attitudes, perspectives, contacts and time available) as dictated by either environmental demands or the development stage of the team" (p. 105). ${ }^{[25]}$ Shared leadership can be a collaborative cushion that smooths out unilateral decision-making, but more so, can leverage the heterogeneous expertise of other team members, especially in response to environmental changes. It is a component of sub-competencies TT7 and TT11: "Share accountability with other professions...", and "Perform effectively on teams and in different team roles..." (p. 14). ${ }^{[8]}$

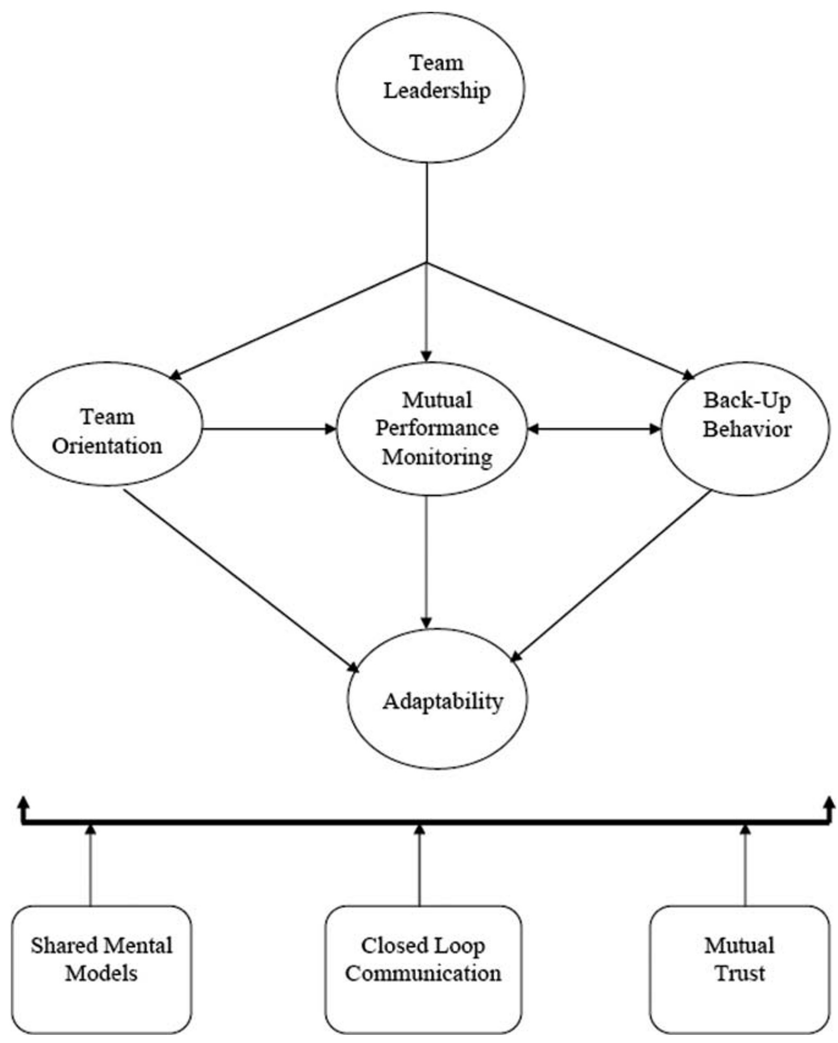

Figure 1. Big Five Model of Teamwork. The big five model of teamwork. (p.345): ${ }^{[24]}$ Copyright 2009 by Sage

Publishing. Reprinted with author permission.

The second of the five in the big model is adaptability, which is performed through a series of phases. Burke et al., defined team adaptation as "a change in team performance, in response to a salient cue or cue stream that leads to a functional outcome for the entire team" (p. 1190). ${ }^{[26]}$ They describe that members of adaptive teams utilize their pooled resources (i.e., knowledge gained from learning) and translate, differentiate, and integrate cues to execute cognitive and behavioral processes, and adjust their actions. Though learning is a precursor, it is not the same as adapting. Adaptive team performance is achieved through four constructs of an adaptive 
cycle: (a) situation assessment, where cue patterns in the environment are recognized and a coherent understanding of the team's present circumstances are built; (b) plan formation, where the team generates a course of action appropriate for the current situation; (c) plan execution, in which the plan is consummated by coordinating mechanisms; and, (d) team learning, whereby the team evaluates the effectiveness of the performance to feed future performance episodes. ${ }^{[24,25]}$ Salas et al., posit that in many contexts team effectiveness directly relates to how the team adapts to multiple conditions and contingencies that they encounter. ${ }^{[21]}$ Both the cyclic and emerging nature of teams directs attention to the importance of time within the team and the recursive attributes of teams. Teams and their members work within, and interact with, organizations and between each other creating dynamic episodes and change. The environment does not necessarily support a linear input, process, and output (IPO) model, but instead the fluidity of team behavior permits pivots and re-direction in response to the environment.

Mutual performance monitoring, the third component of the model, is simultaneously tracking your own work while keeping an eye on other team members' assignments to keep a pulse on how the overall functioning of the team is working. It must be incorporated in the team culture at team formation, so it is not misinterpreted as intrusion, but a welcomed observation of what should be happening. ${ }^{[24]}$ Its advantages are the ability to adjust and coordinate activities between members while taking cues from the external environment to keep on target. ${ }^{[25]}$

The fourth component is back-up behavior described as a discretionary effort recognizing and accommodating a workload distribution problem of the team or assists team members with a task. It can be a physical or verbal aid that can re-adjust strategy, provide feedback or support another in performance. The ability to anticipate the needs of others on the team is through "accurate knowledge about their responsibilities" (p. 560). ${ }^{[21]}$

The final component, team orientation, as described by Salas, Rosen, Held and Weissmuller, is not referring to education or training per se, but is rather, the tendency to use "task inputs of other teammates and patterns of behavior that improve team and individual performance" (p. 346). ${ }^{[24]}$ The input from others avoids some of the stress within teams fostering a team that tends to work as a team, rather than generating stress that may cause team members to focus more on their individual tasks.

Model One coordinating mechanisms. Three distinct coordinating mechanisms act as the operational substrates for the core components to work: (a) shared mental models, (b) closed-loop communication, and (c) mutual trust. ${ }^{[20]} \mathrm{A}$ mental model is a phenomenon created in the mind by a translation of some external process, symbol, or inference. You don't need to know all the properties of something to grasp the way it works. ${ }^{[27]}$ A mental model guided by integration of information, when expanded at the team level, is a shared representation of that information held by one or more team members. A shared mental model of the task by its team members means there are common or overlapping cognitive representations of task requirements, procedures, and role responsibilities. These representations help team members interpret incoming information in a compatible manner and create similar explanations of the environment. ${ }^{[20]}$

A second coordinating mechanism is closed-loop communication. Communication binds the team's work together and doesn't require rationalization. Communication strategies vary, but effective teams often use closed-loop communication as an explicit mechanism for communication. The sender-receiver model of communication is familiar and the common misunderstandings that occur with message misinterpretation. In closed-loop communication the sender follows-up to confirm the message was interpreted as intended.

The third coordinating mechanism is mutual trust. It is fundamental to optimal team functioning and is integral to any organization's or team's capacity to endure the team's tenure with a degree of psychological safety. Mutual trust has been defined as "the shared perception by the majority of team members that individuals in the team will perform particular actions important to its members and that the individuals will recognize and protect the rights and interests of all the team members engaged in their joint endeavor" (p. 205). ${ }^{[28]}$ However, intervening factors may integrate micro-level (psychological processes and group dynamics) with macro-level (institutional arrangements), and can change the conditions for which trust emerges, such as the conditions of risk and interdependence. ${ }^{[29]}$

\subsubsection{Model two}

Model Two describes inputs, throughputs or processes, and two different outcomes to understand team performance. The model emphasizes team characteristics throughout the team's goal pursuit and not the typical business or quality references. Though one output is the output of services, products, and programs (the organizational goal of the team), another outcome is the result of the team's interaction, such as team skills and team knowledge. An earlier version of this model was described by Tannebaum, Beard, and Salas. ${ }^{[22]}$

Team inputs include individual and team characteristics (including its physical and financial resources). The throughputs 
are the manner by which the team interacts over a period of time. They are the processes through which the team communicates, coordinates, makes decisions, and converts its inputs into outputs. The primary outputs are the quality and quantity of the products produced and the services delivered, as reflected in the team's performance. Other outputs are changes in the team (e.g., new norms) and changes in individuals (e.g., improved skills), which in turn may influence subsequent team performance (p. 122). ${ }^{[24]}$

A version of this model was reproduced by Salas, Rosen, Held and Weissmuller ${ }^{[24]}$ and is depicted in Figure 2.

Ilgen, Hollenbeck, Johnson, and Jundt further reflected on this model to describe teams as multi-level systems shaped by the contexts of people, tasks, and technology settings. ${ }^{[18]}$ They suggested the IPO falls short of seeing teams as adaptive systems. Their position was that the process $(\mathrm{P})$ was not necessarily the influence that bridged inputs to outcomes, but other emergent cognitive or affective states. They suggest teams don't function in a linear single path but are influenced by intervening events. Therefore, they promoted an IMOI model, "input, mediators, output and input" (p. 520). ${ }^{[18]}$ substituting $\mathrm{M}$ for $\mathrm{P}$, to explain the variability and mediator influences of teams. Another "I" was suggested at the end (IPOI) to indicate the cyclical performance of teams, wherein the performance output serves to contribute to the input of the next cycle.

\subsection{Characteristics that make a difference}

The structure of teams depicted in Models One and Two are significant contributions to team success without which behaviors may fail to yield the desired outcome. Many organizations have gravitated to distributed leadership, manifested in teams and teamwork. The hierarchical structures are less obvious and decisions are through shared processes, often replacing, modifying, or substituting for traditional vertical models of leadership. ${ }^{[30]}$ However, whatever the structure, characteristics of teams and their members have emerged. The literature is replete with references to many attributes that contribute to team success.

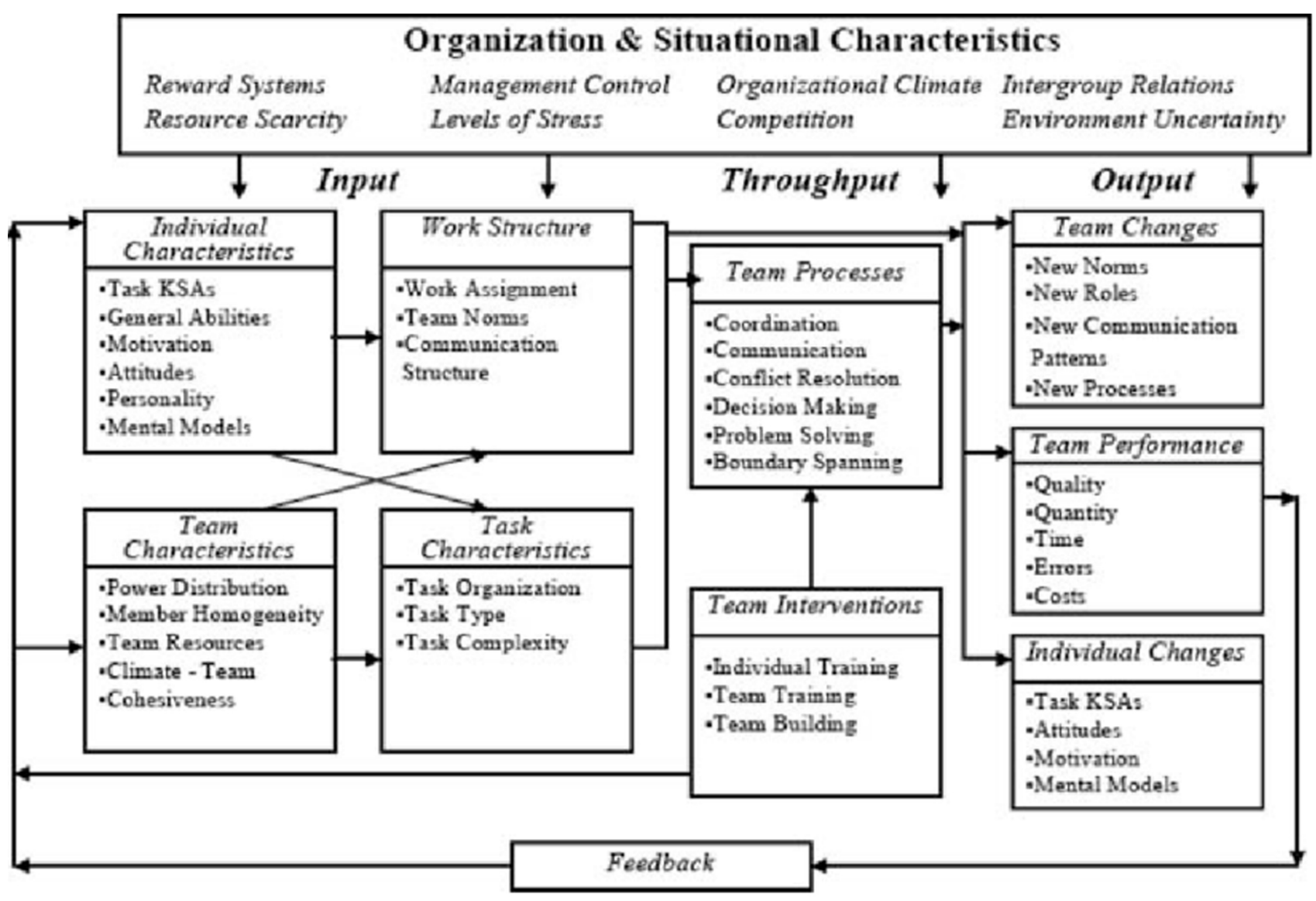

Figure 2. The Team Effectiveness Framework. ${ }^{[24]}$ Copyright 2009 by Sage Publishing. Reprinted with author permission. $K S A=$ knowledge, skills, and attitudes 


\subsubsection{Empowerment}

Team models require empowerment to operate successfully. Empowerment has been described by differentiating how empowerment occurs through structural or psychological means. Structural empowerment usually entails an alteration of the role of external leadership that shifts responsibilities to the team members and often means authority is delegated to team members for a given level of functioning and decisionmaking. In the psychological state, empowerment is perceived as task-autonomy or as a degree of self-determination with which one experiences authority and responsibility. ${ }^{[31]}$ The two are not necessarily exclusive: structural empowerment may be an antecedent to the psychological state. Empowerment may also evolve within teams as an emerging state as empowered teams feel liberated to act, align and coordinate actions to meet goals, handle conflicts, and motivate members. One definition of psychological empowerment is " 'team members' collective belief that they have the authority to control their proximal work environment and are responsible for their team's functioning" (p. 98). ${ }^{[31]}$

\subsubsection{Trust and psychological safety}

Trust and psychological safety are coupled together due to their inextricable links. Trust is likely to be both an antecedent and a consequence of, psychological safety. Rousseau, et al. stated that "trust is a psychological state comprising the intention to accept vulnerability based upon the positive expectations of the intentions or behavior of another" (p. 395). ${ }^{[29]}$ While mutual trust has been described as one coordinating mechanism, in Model One's construction, ${ }^{[20]}$ the expertise enlarged by cross functional teams, differences in language, culture, and practices can create trust barriers at team inception and is a challenge for cohesion development. ${ }^{[28]}$ Webber suggested choosing a high profile, career-impacting project as a precursor to motivating team trust by attracting known talent. ${ }^{[28]}$ Though this notion is an extrinsic factor of trust, the position comes from the belief that talent is functionally defined by past performance and can transfer to an initial sense of trust within the team. Initial impressions of expertise, reputation, and observations based on prior work experiences form the first images of trust and can expedite or postpone conferred trust. Team climate evolves over time and trust can decline and resurface in long standing relationships. ${ }^{[29]}$

Trust is an essential ingredient for psychological safety. Edmundson defines psychological safety as: "the shared belief that the team is safe for interpersonal risk taking... The term is meant to suggest neither a careless sense of permissiveness, nor an unrelentingly positive affect but, rather, a sense of confidence that the team will not embarrass, reject, or punish someone for speaking up. This confidence stems from

Published by Sciedu Press mutual respect and trust among team members" (p. 354). ${ }^{[32]}$

Trust is a tacit belief that is translated into a group construct of being comfortable within the group to be yourself. Edmundson posits that psychological safety is a requirement for optimal team learning. According to Edmundson, "Examples of learning behavior include seeking feedback, sharing information, asking for help, talking about errors, and experimenting. It is through these activities that teams can detect changes in the environment, learn about customers' requirements, improve members' collective understanding of a situation, or discover unexpected consequences of their previous actions" (p. 351). ${ }^{[32]}$ The degree of intrapersonal or interpersonal threat a person perceives makes a substantial difference on how one interacts with the team, how much and what information is disclosed.

\subsubsection{Psychological collectivism}

Psychological collectivism has gained increased interest as employers increasingly align rewards with shared achievements among workers. Highly collective individuals see themselves as members of in-groups, with a strong connection to, and priority for, the well-being and goals of that group. ${ }^{[33]}$ Of interest, is the attention devoted to collectivism, and its counterpart, individualism, each of which has been examined for their cultural attributes and are observable during team interactions. Collectivists have closely aligned personal and communal goals. They subordinate individual needs to group needs. Cognitions conform to norms and obligations of the group. The emphasis is on maintaining relationships, even when it may be disadvantageous. In contrast, individualists weigh the advantages and disadvantages of a relationship. Individualists are likely to focus on their personal needs, rights and contracts to guide their social behavior. If group norms are inconsistent with self needs, norms are likely to be rejected. ${ }^{[34]}$ Therefore, the self is defined within an interdependent behavioral framework for collectivists and within an independent behavioral framework for individualists. The implications may be extended to a better understanding of just how individual preferences and professional cultures guide behavior. Specifically, the application to teams is illustrated in a study conducted by Jackson et al. who found collective members "formed their group tasks better, contributed more discretionary citizenship (give more than receive; reciprocate in a deep concern for the group), and less likely to engage in counterproductive behaviors" (p. 894). ${ }^{[33]}$

\subsubsection{Supportive behaviors}

Setting a goal for the team is a requisite for performance, but for goal-setting to work, team members must feel an attachment to the goal. ${ }^{[10,35]}$ When task interdependence is high, team goal commitment is more strongly related to 
team performance. ${ }^{[10]}$ Supportive behaviors are voluntarilyprovided assistance, defined as either instrumental support, i.e. tangible help with difficult tasks, or emotional, i.e. providing encouragement and positive feedback, and bolstering self-worth. Supportive behaviors mediate the relationship between team goal commitment and team performance. ${ }^{[10]}$

\subsubsection{Self-awareness}

A competency not explicitly listed in IPEC's sub-competency listing is self-awareness, but it is implied through selfreflection and has relevance for its role to help mitigate conflict within teams. The Johari window is a framework developed by Joseph Luft and Harry Ingham in 1955. They described four distinct quadrants to help explain the degrees of self-awareness to which our behaviors are known to the self and to others. ${ }^{[36]}$ The first quadrant is known to the self and known to others and is called the open quadrant. The second quadrant is labeled the blind quadrant and is usually manifested in behaviors that are obvious to others, but the same perceptions or interpretations are not recognized by the individual. The third quadrant is called the hidden quadrant. Characteristics are known to the self, yet consciously hidden from others. These are often qualities individuals are unwilling or not ready to share and are often deflected by a façade. The fourth quadrant is described as the unknown quadrant, a part of the self that is unknown to others and to the self. ${ }^{[36]}$ Feelings, experiences, and the resulting behavior may not be consciously accessible. The four quadrants represent the total person in relation to others and one's awareness of behavior, feelings, and motivation. ${ }^{[37]}$

The importance self-awareness is our ability to self-reflect accurately, use personality strengths, and address weaknesses to enhance team member and team leadership effectiveness. ${ }^{[37]}$ If colleagues sense that we are not open to feedback, or it is always met with resistance, resentment or a lingering downside, feedback is inhibited, the open quadrant shrinks, and the other quadrants get larger. ${ }^{[36]}$ A desire to move from the real to the ideal-self means connecting with one's values, strengths and weaknesses to promote the creation of at least a mental action plan for reaching the ideal. The presumption is that as blind spots diminish, one takes action to consciously correct misdirected behavior to improve relationships. The individual's capacity for self-awareness, and to maintain personal integration and integrity is a likely precursor to entering a positive relationship with others. Selfawareness has significant implications for the competence to fulfill TT6 and TT8: "Engage self and others to constructively manage disagreements...", and "Reflect on individual and team performance..." (p. 14). ${ }^{[8]}$

\subsubsection{Emotional intelligence}

Akin to self-awareness is the construct of emotional intelligence. Jordan and Troth (2004) adopted a model first put forth by Mayer and Salovey worthy of explicating:

a model of emotional intelligence that encompasses (a) perception, (b) assimilation, (c) understanding, and (d) management of emotions. This model emphasizes that emotional intelligence is a multidimensional construct and that these four steps are iterative in that each factor contributes to the development of other factors. 'Perception' refers to an ability to be self-aware of emotions and to express emotions and emotional needs accurately to others. A part of this self-awareness is the ability to distinguish between accurate and inaccurate expressions of emotions and honest and dishonest expressions of emotions. 'Assimilation' refers to an individual's ability to use emotions to prioritize thinking by focusing on important information that explains why feelings are being experienced. This factor also includes the ability to adopt multiple perspectives to assess a problem from all sides, including pessimistic and optimistic perspectives. 'Understanding', the third component of emotional intelligence, refers to an individual's ability to understand complex emotions, such as simultaneously feelings of loyalty and anger. Finally, 'emotional management' revolves around the regulation of emotions - that is an individual's ability to connect or disconnect from an emotion depending on its usefulness in any given situation (pp. 197-198). ${ }^{[38]}$

In their study, Jordan and Troth posited that emotional intelligence will influence the problem-solving performance of teams through individual team members' ability to successfully resolve conflict. They also advanced that functional conflict (resolved constructive conflict) and dysfunctional conflict (unresolved, recurring conflict) is essentially emotional because of the threats to individual or group goals. From the hypotheses posited, their results suggested not all tasks benefit from emotional intelligence. But, when the task at the individual level was subject to a group condition, the task conflict can be emotional, especially if it poses a threat to individual goals or self-esteem. Further, they found teams with high average emotional intelligence are more likely to adopt collaborating conflict relationship styles to resolve conflict versus teams with lower average levels of emotional intelligence. ${ }^{[39]}$ Therefore, emotional intelligence may be a decisive element to fulfill TT6.

\subsection{Team leadership and facilitation}

According to Salas, Sims and Burke, team leaders enable effective teamwork and interdependent action through three overarching functions. While reflected in Model One, these standalone without a reliance on a model. First, the team 
leader has a role in the creation, maintenance, and accuracy of the team's shared mental model. ${ }^{[21]}$ Throughout the team's lifespan, the leader establishes and re-establishes a shared understanding of the team objectives, the team constraints, its resources, and the role of each team member. Empirical evidence by Marks, Zaccaro, and Mathieu indicates that the provision of enriched information by team leaders results in more similar and accurate mental models among team members. ${ }^{[40]}$

Second, the team leader promotes team effectiveness by monitoring the environment to facilitate team adaptability and by using this information to produce an appraisal of the operating environment. ${ }^{[41]}$ The third function of the team leader is establishing behavioral and performance expectations. Early on, social structure, communication, norms, and role expectations need to be established particularly at a time when the team is more receptive and the basis for collective action can be more easily determined and accepted. ${ }^{[41]}$ If nonproductive team conflict arises, the leader must reestablish adaptive norms and performance expectations. ${ }^{[41]}$ Leaders must be aware of the strengths and weaknesses of each team member and how these intersect with task requirements to coordinate team behaviors and interactions. ${ }^{[41,42]}$ This third function of the team leader particularly relates to Core 4 sub-competency TT8: "Reflect on individual and team performance for individual. . team, performance improvement" (p. 14). ${ }^{[8]}$

Facilitative leadership refers to acts that "promote respect and positive relationships between team members, productive conflict resolution and open expression of ideas and opinions" (p. 312). ${ }^{[43]}$ It merges with Core 4 sub-competencies TT3 and TT4: "Engage health and other professionals in shared...problem solving...", and "Integrate the knowledge and experience of health and other professions..." (p. 14). ${ }^{[8]}$

If we assume a critical characteristic of team leadership is facilitation, then constructs embedded in leadership skills may be pragmatically employed for good facilitation. For instance, a definition of authentic leadership particularly advances the competencies laid out by IPEC: "a pattern of transparent and ethical leader behavior that encourages openness in sharing information needed to make decisions while accepting followers' inputs" (p. 422). ${ }^{[30]}$ The connection with facilitation is importantly linked with four components posited as important attributes of authentic leadership: (a) balanced processing (objectively analyzing relevant data before making a decision, (b) internalized moral perspective (guided by internal moral standards, used to self-regulate); (c) relational transparency (presenting one's authentic self through openly sharing information and feelings, appropri-

Published by Sciedu Press ate for situations, but not inappropriate displays of emotion); and, (d) self-awareness (demonstrated understanding of one's strengths and weaknesses, and the way one makes sense of the world). ${ }^{[30]}$ By the nature of interprofessional collaboration each team member takes on a quasi- leadership role at various times of the team's tenure depending on the problem to be solved. Therefore, each member may require equivalent levels of authentic leadership acumen. TT11 states: "Perform effectively on teams and in different team roles..." (p.14). ${ }^{[8]}$ CHIC created Domain 5: "collaborative leadership", which acknowledges the shared decision-making and the application of leadership principles required amongst team members. ${ }^{[1]}$ IPEC also coupled leadership with collaboration in Core sub-competency TT5: "apply leadership practices that support collaborative practice..." (p. 14). ${ }^{[8]}$

\subsection{Team conflict}

Good facilitation assumes the capacity to adequately address team conflict. As described, self-awareness and emotional intelligence are also essential components for both team leaders and team members to successfully promote positive dialogue in response to the concurrent and inevitable disagreements that surface. CHIC emphasized the importance of conflict management by its separate distinction in Domain 6, interprofessional conflict resolution. ${ }^{[1]}$ IPEC incorporates it in TT6: "Engage... others to constructively manage disagreement..." (p. 14). ${ }^{[8]} \mathrm{CHIC}$ recognized disagreements often relate to ambiguity, power gradients, and differences in goals. ${ }^{[1]}$ Gardner addresses team conflict by explaining that role status in hierarchical systems can convey a power level that causes an imbalance between members of the team. ${ }^{[44]}$ Behaviors such as diminishing the team's performance through talking about other team members' inadequate competencies, and "social loafing" (free riding) amongst some team members demotivate the group and are also a source of team conflict. ${ }^{[40]}$ Conflict may also emanate from a structural source. Multiple reporting relationships amongst members create confusing expectations for performance, competing priorities and conflicts between members of the team, and between their respective functional managers. ${ }^{[28]}$

The manifestations of team conflict may create different approaches. Conflict triggers can be anticipated and identified to set agreements, such as charters, by which these will be effectively managed. Task conflict can usually be addressed on a cognitive level especially when the groundwork for task conflict discussion was formed at the beginning of the team's formation. Interpersonal and/or emotionally-tied conflict can be more difficult to address successfully. Marks and others differentiate conflict management into two types: “(1) preemptive conflict management involves establishing con- 
ditions to prevent, control, or guide team conflict before it occurs; and (2) reactive conflict management involves working through task, process, and interpersonal disagreements among team members" (p. 368). ${ }^{[40]}$ Team contracts and charters can lay out ground rules, norms, and how teams will handle conflict before the team starts its work. ${ }^{[16,21,40]}$

Affect management calibrates team members' emotions and may deescalate reactive conflict. Amason posits that evidence strongly supports dialectical inquiry (DI), a technique to prompt critical and investigative interaction between members, results in better decision-making, but Amason also maintains that team members need a level of positive affective relationships to work together effectively. Diversity of experiences is critical for high quality decision making and cognitive disagreement may be deliberately induced. Yet, efforts to incite the percolation of ideas and create cognitive tension may lead to conflict that is dysfunctional. ${ }^{[45]}$ Cognitive disagreement can lead to emotional or affective conflict. Affective conflict seems to emerge when cognitive disagreement is interpreted as personal criticism or "political gamesmanship ... the results of which... can foster cynicism, avoidance, or countereffort" (p. 129). As team leaders induce cognitive conflict, they may cause an unnoticed "mutation" and trigger affective conflict (p.129). ${ }^{[45]}$ A study by Amason found cognitive conflict accounted for the improvement in decision making quality and it was also positively related to affective acceptance amongst groups. ${ }^{[45]}$ Affective conflict however had an adverse effect on decision making, which might further explain why affective conflict and quality decision making are unlikely to co-exist well.

Barsade and Gibson contend that emotions are part of group life. Group emotion has been described as the collective emotions that get produced from the interaction within the group and the net effects from the individual profiles or make-up of each group member. They describe the phenomenon as a "group as a whole approach", one that can influence the behaviors of individuals within it. ${ }^{[46]}$ In this perspective, individual emotions can be subsumed in group emotions and can result in a group emotional character that is more extreme than individuals would exhibit. To illustrate with an exaggerated example, the phenomenon can emerge when the homogeneity of emotions is enveloped in a crowd mentality. First described by Freud, two processes explicate the phenomenon: (a) impulsivity, an increased comfort amongst members to translate ideas into action, and (b) a mass contagion, where individuals imitate the emotional character of others in the group. Freud depicted "the dwindling of the conscious individual personality and the focussing [sic] of thoughts and feelings into a common direction... corresponds to a regression... to a state of primitive mental activity" (p. 91). ${ }^{[47]}$
Though crowd mentality is an extreme instance, by its extreme, it helps us imagine the degree to which groups may congeal emotion and may blunt the emotional variation between individuals towards a cause, which does not differentiate the self. Both components work together to escalate team behavior, and without a moderator, can be destructive. Moderation occurs through leader-facilitation, but it is also a function of team-member's self-regulation through individual attributes of self-awareness and emotional intelligence.

\subsection{Collaboration}

IPEC repositioned Collaboration as the theme that invokes and directs the 4 core competencies. Gardner proposed that collaboration is both a process and an outcome by seeing the collaborative process as a synthesis of different perspectives, and the collaborative outcome as the development of integrative solutions that could not be achieved by a single person or organization. She contends that communication and cognitive diversity can be optimized by understanding work styles, expanding communication repertoires and appreciating inquiry. ${ }^{[4]}$ In other words, be attentive to team members' values, goals and ways of engagement. She posited several lessons for putting collaboration into practice.

Though collaboration focuses on what and how communication happens within teams, it has become complex with the web of professions becoming more intertwined with public and private bureaucracies. According to Barr, different professions have experienced enhanced status, new professions have emerged, territory has been gained and lost, and responsibilities reallocated, all of which have shifted power. The evolution prompts disequilibrium, and it is magnified by empowered consumerism. "Competition and collaboration coexist" and this reality crosses several professional and industry sectors (p. 182). ${ }^{[3]}$ Hence, the context at a macro and micro level within which we strive for collaboration continues to evolve. Barr also elaborated on the importance of distinguishing competencies within and between professions by defining common, complementary and collaborative categories. ${ }^{[3]}$ Collaborative competencies acknowledge the roles, responsibilities and competencies of others while tolerating ambiguities and recognizing their constraints.

Others have found role recognition and role clarity, along with working together over time made a positive difference for collaboration. ${ }^{[48]}$ Further, relationship perception may improve when there was a better understanding that one professional could accept a suggestion from another, but not have the burden of implementing it. Suter, Arndt, Arthur, and others found role understanding and appreciation helps collaboration; yet, also found that professional culture may enhance care by diverse participation, but it may impede 
collaborative practice. ${ }^{[49]}$

Some authors suggest that barriers intrinsic to academic training within healthcare personnel still prevail and represent primary hurdles to collaboration and teamwork. These barriers often begin with a taught professional identity that is preserved and protected, often at the exclusion of others and may be perpetuated in practice with status asymmetries, ambiguous roles, and interpersonal power. ${ }^{[50,51]}$ Reeves, van Soeren, MacMillan, and Zwarenstein suggest that regulatory bodies and legal frameworks control professional entry and scope of practice, perpetuating isolationism versus collaboration. They posit that a social contract, particularly for nurses and physicians, could outline roles/responsibilities between each other and with the public too. ${ }^{[52]}$ A social contract might delineate work and serve as the basis for interprofessional negotiation.

\section{Discussion}

Team training and team-building exercises within organizations are an important factor to form successful teams. ${ }^{[22,53,54]}$ TeamSTEPPS $\AA$ is one kind of packaged team training directed for clinical use to improve patient safety. ${ }^{[19,55,56]}$ Others may incorporate simulation techniques, team adaptation, and error management training. ${ }^{[23]}$ Some advocate harnessing individual and collective expertise by leveraging all team learning opportunities within organizations. Nisbet, Lincoln, and Dunn contend that workplace learning is informal interprofessional learning where learning occurs in everyday practice, can and should be more explicit, and may teach professionals how to utilize the expertise of the team to be a more competent interprofessional practitioner. They suggest a creation of a learning organization that maximizes learning for improvement in performance, safety, outcomes, and practice. ${ }^{[57]}$ Importantly, "team training is a cultural intervention and dependent upon leadership support at all levels" (p. 370). ${ }^{[58]}$

Another consideration to effectively teach, train, and disseminate IPEC competencies is to assimilate them with quality methodologies. Health care settings are fraught with patient/client variables with a need to periodically function as HRTs. Alternatively, multiple processes that indirectly drive care and services do not function as HRTs, nor should they. Quality processes are used for both. Specifically, IPEC's TT9 states: "Use process improvement to increase effectiveness of interprofessional teamwork and team-based services, programs, and policies" (p. 14) ${ }^{[8]}$ Process models such as TeamSTEPPS $\AA$, Plan Do Study and Act (PDSA), and Lean Six Sigma (LSS) need to form a tight fit with IPEC competencies to avoid a number of overlapping models. Though quality methodologies with several tools have been implemented in many clinical settings how IPEC competencies complete or contribute to these methodologies are not explicit. ${ }^{[23,59]}$

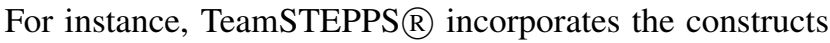
of shared mental models, mutual support, situational monitoring, back up behavior, closed loop communication, and others through its tools, mnemonics, and acronyms. These are adopted and adapted for specific clinical presentations and encounters. Despite their usefulness and appeal to institutions, we need to explain how these tools are represented within the context of IPEC competencies, particularly Core $4 \mathrm{TT}$, to deepen the understanding amongst professionals to expand and illustrate their broader connection. Health care professionals should know how to integrate quality processes with IPEC competencies as the overarching goal. Overlapping models confuse desired goals particularly for professionals at entrance into practice with the conflicting priorities of institutions and practitioners. Instead, models can be articulated together so they are more easily understood and adopted for ease of widespread application.

Notwithstanding team training, a deeper understanding of human behavior is often a prevailing factor in a team's success. Yet, the challenge to better understand which behaviors make a difference continues. The psychological and sociological bases for member interactions are critical to our understanding of teamwork and representative disciplines have made significant contributions to the literature. Healthcare professions need to cast a wider net and tap into these professions with more intensity than we have in the past. Reeves suggested that the value of sociology can provide critical framing to "micro interactions" between professions (p.218) ${ }^{[60]}$ And, according to Weingart and Cronin, it is time to unify constructs and organize the knowledge already produced. They assert continued identification of new effects, the infinite possibilities and the renaming of phenomena produces construct proliferation that is not "cognitively manageable" (p. 510). ${ }^{[61]}$ The merits of consolidation should be recognized, but not at the expense of defining what behaviors work. Studies that demonstrate how outcomes are affected by team behavior remain unapparent. The reasons may be in the subject. Human behavior is iterative. It evolves over time with self- and team-awareness, and team learning. Behavior is also prompted by context, changing conditions and is often circumstantial. The dynamics create a moving target, where it is difficult to predict states for study control and link teamwork to outcomes. ${ }^{[62]}$

When the Core 4 TT sub-competencies are examined, the operative terms and phrases for success such as engagement, shared problem-solving, team leadership and conflict resolution functionally have a dependence on the behavioral attributes described. While these may be innate for some 
individuals, for most of us these are learned. To succeed we rely on the structural components or models as one scaffold for the vehicle through which we enact behaviors, but the mastery of team leadership and conflict resolution relies on the motivation to collaborate.

Table 2. Guidelines for the "how" of competency development

\begin{tabular}{|c|c|}
\hline \multicolumn{2}{|r|}{ TEAM LEADER } \\
\hline Behavior/Topic & Actions \\
\hline $\begin{array}{l}\text { Understand the knowledge, skills } \\
\text { and abilities (KSA's) of each } \\
\text { member }\end{array}$ & $\begin{array}{l}\text { Specify and verify each KSA with team members. Conduct initial interviews to assess the status of KSA's, and their contribution to } \\
\text { shared mental models. }{ }^{[25,63]}\end{array}$ \\
\hline $\begin{array}{l}\text { Set the foundation and the } \\
\text { ongoing team performance } \\
\text { expectation. }\end{array}$ & $\begin{array}{l}\text { Have a pre-brief before the team begins on the demands of the project. }{ }^{[25,63]} \\
\text { Engage members to know each other, strengths and weaknesses, and motivations. Establish ground rules at the beginning of team } \\
\text { formation and recheck performance periodically. It is the beginning of an unwritten psychological contract. }{ }^{[21,40]} \\
\text { Establish purpose for the team, though this often requires a revisit. }{ }^{[63]} \\
\text { Don't avoid slowing down or re-formation by relying on advocacy (support for a topic or decision) vs. inquiry. Instead, recognize } \\
\text { the fast pace as a challenge, but provide the experience space to help the team adapt and learn by inviting deeper dialogue, rather } \\
\text { than an expedient solution. }{ }^{[63]}\end{array}$ \\
\hline Informant & Share information to team members throughout the life of the team. Help team members understand barriers. ${ }^{[21,42]}$ \\
\hline Shared mental models & $\begin{array}{l}\text { Interview team members for their strengths and weaknesses- share results and develop guidance for a shared understanding. Take } \\
\text { responsibility for the role a leader: develop members' mental models of team goals, actions needed, and how these may change over } \\
\text { time. }{ }^{[25,27,63-64]} \text {. }\end{array}$ \\
\hline Team learning & $\begin{array}{l}\text { Encourage feedback. Discuss errors openly and recap debriefings for a teaching moment; encourage experimentation. Model } \\
\text { behavior by admitting confusion or a mistake and giving team members an opportunity to emulate learning. Self-correct. }{ }^{[24,25]}\end{array}$ \\
\hline Set a climate for trust & $\begin{array}{l}\text { Dig for the root causes of errors, but do not embarrass or punish. }{ }^{[32]} \\
\text { Use errors for learning moments. Promote awareness of each other's competencies. }{ }^{[28,63]}\end{array}$ \\
\hline Psychological Safety & $\begin{array}{l}\text { Trust is a component, but care "for each other as human beings" (p. 411). Both trust and psychological safety should be evidenced } \\
\text { by energy, engagement, and varied opinions. }{ }^{[63]}\end{array}$ \\
\hline $\begin{array}{l}\text { Recognize task-related or } \\
\text { cognitive conflict vs. } \\
\text { interpersonal conflict. }\end{array}$ & $\begin{array}{l}\text { Develop team rules and norms about the nature and timing of conflict. Educate the team to understand the differences between task } \\
\text { and interpersonal conflict and how each will be addressed. Tolerate cooperative approaches and guide against competitive ones. } \\
\text { Discuss multiple ideas to engage multiple views to reconcile and acknowledge their value. Go back to objectives, and highlight to } \\
\text { consider what options are more closely aligned with goals. Recognize conflict for its merit. Use conflict as an opportunity to } \\
\text { develop a shared mental model for the team by articulating differences and building consensus. }{ }^{[0,45,63]}\end{array}$ \\
\hline $\begin{array}{l}\text { Provide training to team members } \\
\text { before a project }\end{array}$ & Behaviors can be learned. Provide didactic and experiential training to teach and mimic successful team behaviors. ${ }^{[65]}$ \\
\hline Post-Briefing & $\begin{array}{l}\text { Provide a time for post-performance or post-action reviews soon after the team or an encounter adjourns. Target task-driven work } \\
\text { and avoid person-based feedback. Include team work processes as a critical element. Address how team interaction affected } \\
\text { performance Probe with open-ended questions and do not be the first one to provide observations and solutions. Encourage } \\
\text { members about being specific about behaviors that helped or hindered an event. If comments are too general— - such as } \\
\text { "communication was poor", it is hard to improve the specific kind, and timing of, communication that needs to improve. Be } \\
\text { specific. Make links between various briefings to provide continuity for a bigger picture of performance; and learning. Voice team } \\
\text { improvements. }{ }^{[43,57,66]}\end{array}$ \\
\hline \multicolumn{2}{|r|}{ TEAM MEMBERS } \\
\hline Behavior/Topic & Actions \\
\hline Communication & $\begin{array}{l}\text { Exchange task-related information. }{ }^{[67]} \text { Communicate openly. }{ }^{[68]} \\
\text { Focus on behaviors and events in a non-evaluative atmosphere. }{ }^{[66]} \text { Ask probing questions to clarify. }{ }^{[44]} \text { Develop a tolerance for } \\
\text { ambiguity. }{ }^{[63,66]} \\
\text { Actively listen (without distraction) and be patient while listening to others. }{ }^{[44]} \\
\text { Build on what others have stated. }{ }^{[6,66]} \\
\text { Own one's communication. Use "I" statements. } .^{[63]} \text { The speaker should discuss the impact others' behavior or actions on him or her } \\
\text { as an observable description, not interpreted. }{ }^{[63]} \\
\text { Inquire, ask questions and clarify to increase understanding. Balance advocacy (for your position) with inquiry to clarify the issues } \\
\text { and open up the dialogue for root causes and other solutions }{ }^{[63,66,68]} \text { Dialogue in this sense means to suspend assumptions and enter } \\
\text { into a genuine "thinking together" (p.10), not a discussion. }{ }^{[68]}\end{array}$ \\
\hline Scan the environment & $\begin{array}{l}\text { Scan the environment; get an external perspective to discover clients'/customers' expectations-it can be a source of new ideas to } \\
\text { expand thinking. It also can be a way of launching a dialogue within the team that is prompted by an external body and thereby is } \\
\text { treated as 'just information' without the inside-team sensitivities. }{ }^{\left[{ }^{63]}\right.}\end{array}$ \\
\hline Engage in deep dialogue & $\begin{array}{l}\text { Getting through the layers of tasks and objectives to develop a shared mental model. Tolerate differences during dialogue in order } \\
\text { to work through to alignment, balancing advocacy with inquiry. }{ }^{[63]}\end{array}$ \\
\hline Shared leadership & $\begin{array}{l}\text { Recognize the competencies and professional domains of one another by asking for opinions and approach problem-solving with } \\
\text { those professionals with a reference to their content expertise. } \text {. }^{25]}\end{array}$ \\
\hline Mutual performance monitoring & $\begin{array}{l}\text { Keep an eye on each other for goal support and team member needs particularly for the tasks to be accomplished. Recognize when } \\
\text { someone needs bolstering either in content or emotional lifting. }{ }^{[24,66]}\end{array}$ \\
\hline Seize moments to develop trust & $\begin{array}{l}\text { Make deposits into an emotional bank account with courtesy, kindness, honesty and keeping commitments so individuals } \\
\text { accumulate a positive net effect of the total of encounters }{ }^{[69]} \text { One study revealed a ratio of five positive interactions to one negative } \\
\text { predicts long lasting relationships. }{ }^{[70]} \text { Collaboration can occur anywhere, in hallways and spontaneously. Leverage these, but } \\
\text { choose the best time to inject your ideas. Opportunities are everywhere. } .^{[4]}\end{array}$ \\
\hline $\begin{array}{l}\text { Practice reflection for } \\
\text { self-awareness }\end{array}$ & $\begin{array}{l}\text { Make personal goals and values explicitly conscious. }{ }^{[71]} \text { Increase self-awareness by reflecting on interactions. Think of what you } \\
\text { may not know about the interaction, especially if your intuition says something did not go well. }{ }^{[44]} \text { Have the courage to ask others } \\
\text { what they think to demonstrate your openness to feedback. }{ }^{[36]}\end{array}$ \\
\hline Practice process skills & $\begin{array}{l}\text { Be present and avoid distraction. The contextual situation within which communication transpires includes power, political forces, } \\
\text { finances and policies, etc. Reflect systems thinking for the sources that have created the context. Merge perspectives to balance } \\
\text { autonomy with the unity required for collaborative relationships. But, be aware of the risk of too much diffusion and the loss of } \\
\left.\text { individual thinking. }{ }^{[4]}\right]\end{array}$ \\
\hline
\end{tabular}


The literature must address what we can glean for useable, concrete practices to guide and attract the attention of endusers now. The healthcare industry is compelled to be effective, efficient, timely and patient-centered and may outpace academic education in its prescription of what works. The financial, healthcare industry and consumer environments are demanding action at a feverish pace with an unfortunate intolerance for protracted rigor. Table 2 is a summary of the "how" components to synthesize and centralize important evidence from the literature and provide useful information to launch and perpetuate teamwork to address IPEC's TT sub-competencies.

\section{Conclusion}

Though the IOM provided the impetus for interprofessional health care team collaboration, it is predominately industry, government-sponsored agencies (e.g. IOM, AHRQ), and other professional and academic bodies such as psychology, sociology, and their sub-disciplines that have informed healthcare professionals about what targets to achieve, but not necessarily how teams and team members may function most successfully. IPEC's TT's competencies guide us to interprofessional collaboration for favorable outcomes but fall short of telling us how these get achieved. The article posits the scaffold begins with structural models, two of which were described. Coupled with this scaffold, are key behavioral ingredients, attributes of team leaders and team members that permit a safe and robust dialogue to propel team success. These were correlated with TT sub-competency statements. While the literature highlights influences, challenges, and in limited cases, determinants of team effectiveness, there is not a comprehensive framework that definitively depicts a triumphant model. More work ahead is needed to study team models and the behaviors directed at, and aligned with, advancing and mastering how competencies are achieved. While a consistent prescription for team success remains elusive, there are undeniable principles and qualities reflected in the literature and described here that prepares us for the competencies outlined in Teams and Teamwork.

\section{CONFliCtS OF INTEREST Disclosure}

The author declares there is no conflict(s) of interest.

\section{REFERENCES}

[1] Canadian Interprofessional Health Collaborative. A national interprofessional competency framework. 2010. Available from: http: //www.cihc.ca/resources/publications

[2] Interprofessional Education Collaborative Expert Panel. Core competencies for interprofessional collaborative practice: Report of an expert panel. 2011; Washington, D.C.: Interprofessional Education Collaborative. Available from: http://www. aacn.nche.edu/ed ucation-resources/ipecreport.pdf

[3] Barr H. Competent to collaborate: Towards a competency-based model for interprofessional education. Journal of Interprofessional Care. 1998; 12(2): 181-187. https://doi.org/10.3109/1356 1829809014104

[4] Institute of Medicine. Educating for the health team. National Academy of Sciences, Washington, D.C. 1972.

[5] Institute of Medicine. To err is human: Building a safer health system. National Academy Press, Washington DC. 2000.

[6] Institute of Medicine. Crossing the quality chasm. National Academy Press, Washington DC. 2001.

[7] Institute of Medicine. Health Professions Education: A Bridge to Quality. National Academy Press, Washington, DC. 2003.

[8] Interprofessional Education Collaborative. Core competencies for interprofessional collaborative practice: 2016 update. 2016; Washington, DC. Available from: http://www. aacn.nche.edu/educ ation-resources/ipecreport.pdf

[9] World Health Organization. Framework for action on interprofessional education and collaborative practice. 2010. Geneva, Switzerland: Author. Available from: http://www.who.int/hrh/nurs ing_midwifery/en/

[10] Aube C, Rousseau V. Team goal commitment and team effectiveness: The role of task interdependence and supportive behaviors. Group
Dynamics: Theory, Research, and Practice. 2005; 9(3): 189-204. https://doi.org/10.1037/1089-2699.9.3.189

[11] Drucker PF. Management's new paradigms. Forbes. 1998; 162(7): 152-170.

[12] Marks MA, DeChurch LA, Mathieu JE, et al. Teamwork in multiteam systems. Journal of Applied Psychology. 2005; 90(5): 964-971. PMid:16162068 https://doi.org/10.1037/0021-9010.90.5 .964

[13] Heget JR, Bagian JP, Lee CZ, et al. System innovation: Veterans Health Administration National Center for Patient Safety. Joint Commission Journal Quality Improvement. 2002; 28(12): 660-665. https://doi.org/10.1016/S1070-3241(02) 28071-2

[14] Salas E, Rosen MA. Building high reliability teams: progress and some reflections on teamwork training. Quality and Safety in Health Care. 2013; 22: 369-373.

[15] Weick KE, Sutcliffe KM, Obstfeld D. Organizing for high reliability: Processes of collective mindfulness. In R.S. Sutton and B.M. Staw (Eds.), Research in Organizational Behavior. Jai Press, Stanford. 1999.

[16] Pande PS, Neuman RP, Cavanagh RR. The Six Sigma Way. McGrawHill, New York. 2002.

[17] Pyzdek T, Keller P. The Six Sigma Handbook. 3rd Ed. McGraw Hill, New York. 2010.

[18] Ilgen DR, Hollenbeck JR, Johnson M, et al. Teams in organizations: From input-process-output models to IMOI models. Annual Review of Psychology. 2005; 56: 517-543. PMid:15709945 https: //doi.org/10.1146/annurev.psych.56.091103.070250

[19] Agency for Healthcare Research and Quality. TeamSTEPPS ( Instructor Manual. March, 2014. Rockville, MD. Available from: http://www. ahrq.gov/professionals/education/curri 
culum-tools/teamstepps/instructor/reference/ackno wl.html

[20] Salas E, Rosen MA, Burke CS, et al. The wisdom of collectives in organizations: An update of the teamwork competencies: Crossdisciplinary perspectives and approaches. In E. Salas, G. F. Goodwin, \& C.S. Burke (Eds.), Team effectiveness in complex organizations. Psychology Press, New York. 2009; 39-79.

[21] Salas E, Sims DE, Burke S. Is there a big five in teamwork? Small Group Research. 2005; 36(5): 555-599. https ://doi.org/10.1 $177 / 1046496405277134$

[22] Tannenbaum SI, Beard RL, Salas E. Team building and its influence on team effectiveness: An examination of conceptual and empirical developments. In K. Kelley (Ed.), Issue, theory, and research in industrial/organizational psychology. Elsevier, Amsterdam. 1992; 117-153.

[23] Weaver SJ, Dy SM, Rosen MA. Team-training in healthcare: A narrative synthesis of the literature. BMJ Quality and Safety. 2014; 23(5): 359-372. PMid:24501181 https://doi.org/10.1136/bmjqs-2 013-001848

[24] Salas, E, Rosen MA, Held JD, et al. Performance measurement in simulation-based training: A review and best practices. Simulation and Gaming. 2009; 40(3): 328-76. https://doi.org/10.1177/ 1046878108326734

[25] Burke CS, Stagl KC, Salas E, et al. Understanding team adaptation: A conceptual analysis and model. Journal of Applied Psychology. 2006; 91(6): 1189-1207. PMid:17100478 https ://doi.org/10.1 037/0021-9010.91.6.1189

[26] Burke CS, Fiore SM, Salas E. The role of shared cognition in enabling shared leadership and team adaptability. In C. L. Pearce \& J. A. Conger, (Eds.), Shared leadership: Reframing the hows and whys of leadership. Sage; Thousand Oaks, CA. 2004; 103-121.

[27] Johnson-Laird P. Mental models. Harvard University Press, Cambridge, MA. 1983.

[28] Webber SS. Leadership and trust facilitating cross-functional team success. Journal of Management Development. 2002; 21: 201-214. https://doi.org/10.1108/02621710210420273

[29] Rousseau DM, Sitkin SB, Burt RS, et al. Not so different after all: A cross-discipline view of trust. Academy of Management Review. 1998; 23: 393-404. https ://doi.org/10.5465/amr.1998.926 617

[30] Avolio B, Walumbwa F, Weber T. Leadership: Current theories, research, and future directions. Annual Review of Psychology. 2009; 60: 421-449. PMid:18651820 https ://doi .org/10.1146/annu rev.psych.60.110707.163621

[31] Mathieu JE, Gilson LL, Ruddy TM. Empowerment and team effectiveness: An empirical test of an integrated model. Journal of Applied Psychology. 2006; 91(1): 97-108. PMid:16435941 https : //doi.org/10.1037/0021-9010.91.1.97

[32] Edmondson A. Psychological safety and learning behavior in work teams. Administrative Science Quarterly. 1999; 44: 350-383. https : //doi.org/10.2307/2666999

[33] Jackson CL, Colquitt JA, Wesson MJ, et al. Psychological collectivism: A measurement validation and linkage to group member performance. Journal of Applied Psychology. 2006; 91(4): 884-899. PMid:16834512 https ://doi .org/10.1037/0021-9010.91.4 .884

[34] Triandis HC. Individualism and collectivism. Westview Press; Boulder, CO. 1995.

[35] Weldon E, Weingart L. Group goals and group performance. British Journal of Social-Psychology. 1993; 32: 307-334. https ://doi .or $\mathrm{g} / 10.1111 / \mathrm{j} \cdot 2044-8309.1993 . \mathrm{tb01003} \cdot \mathrm{x}$
[36] Quinn RE, Faerman SR, Thompson MP, et al. Becoming a master manager: A competing values approach. Wiley, New Jersey. 2014.

[37] Patten Jr TH. Organizational development through teambuilding. Wiley, New York. 1981

[38] Mayer JD, Salovey P. What is emotional intelligence? In PA Salovey \& D. Sluyter (Eds.). Emotional development and emotional intelligence: Implications for educators. Basic Books, New York. 1997; 3-31.

[39] Jordan PJ, Troth AC. Managing emotions during team problem solving: Emotional intelligence and conflict resolution. Human Performance. 2004; 17(2): 195-218. https ://doi.org/10.1207/s153 27043hup1702_4

[40] Marks MA, Mathieu JE, Zaccaro SJ. A temporally based framework and taxonomy of team processes. Academy of Management Review. 2001; 26: 356-376. https://doi.org/10.5465/amr.2001.484 5785

[41] Zaccaro SJ, Heinen B, Shuffler M. Team leadership and team effectiveness. In E. Salas, G. F. Goodwin, \& C. S. Burke (Eds.) Team effectiveness in complex organizations. Psychology Press, New York. 2009; 83-111.

[42] Zaccaro SJ, Rittman AL, Marks MA. Team Leadership. Leadership Quarterly. 2001; 12: 451-483. https://doi.org/10.1016/S104 8-9843(01) 00093-5

[43] Hirst G, Mann L, Bain P, et al. Learning to lead: The development and testing of a model of leadership learning. Leadership Quarterly. 2004; 15: 311-327. https://doi.org/10.1016/j.leaqua. 200 4.02 .011

[44] Gardner D. Ten lessons in collaboration. Online Journal of Issues in Nursing. 2005; 10(1).

[45] Amason AC. Distinguishing the effects of functional and dysfunctional conflict on strategic decision-making: Resolving a paradox for top management teams. Academy of Management Journal. 1996; 39: 123-148.

[46] Barsade SG, Gibson DE. Group emotion: A view from the top and bottom. In D. H. Gruenfeld (Ed.) Research of managing groups and teams. JAI Press, Stamford, CT. 1998; 81-102.

[47] Freud S. Group psychology and the analysis of the ego (Trans. James Strachey). W. W. Norton, New York. 1922.

[48] Makowsky MJ, Schindel TJ, Rosenthal M, et al. Collaboration between pharmacists, physicians, and nurse practitioners: A qualitative investigation of working relationships in an inpatient medical setting. Journal of Interprofessional Care. 2009; 23(2): 169-184. PMid:19234987 https ://doi.org/10.1080/13561820802602 552

[49] Suter E, Arndt J, Arthur N, et al. Role understanding and effective communication as core competencies for collaborative practice. Journal of Interprofessional Care. 2009; 23(1): 41-51. PMid:19142782 https ://doi.org/10.1080/13561820802338579

[50] Meleis AI. Interprofessional education: A summary of reports and barriers to recommendations. Journal of Nursing Scholarship. 2015; 48(1): 106-112. PMid:26642299 https ://doi.org/10.1111/jn u. 12184

[51] Mitchell PH, Robins LS, Schaad D. Creating a Curriculum for training health profession faculty leaders. In K. Henriksen, J. B. Battles, E. S. Marks, \& D. I. Lewin. (Eds.). Advances in patient safety. Agency for Healthcare Research and Quality, Rockville, MD. 2005; 299-312.

[52] Reeves S, van Soeren M, MacMillan K, et al. Medicine and nursing: A social contract to improve collaboration and patientcentered care? Journal of Interprofessional Care. 2013; 27(6): 441442. PMid:24299578 https://doi.org/10.3109/13561820.2 013.846033 
[53] Brock D, Abu-Rish E, Chiu CR, et al. Postgraduate Medical Journal. 2013; 89: 642-651.

[54] Weaver SJ, Rosen MA. Making health care safer II: An updated criteria analysis of the evidence for patient safety practices (Evidence reports/technology assessments, No. 2011). Agency for Healthcare Research and Quality. Rockville, MD. 2013.

[55] Agency for Healthcare Research and Quality. TeamSTEPPS 2.0. December, 2015. Rockville, MD. Available from: http://www.ahrq.gov/professionals/education/cur riculum-tools/teamstepps/instructor/index.html

[56] Agency for Healthcare Research and Quality. TeamSTEPPS $₫$ for Office-Based Care Version. March, 2016. Rockville, MD. Available from: http://www.ahrq.gov/professionals/education/c urriculum-tools/teamstepps/officebasedcare/index. html

[57] Nisbet GM, Lincoln S. Informal interprofessional learning: An untapped opportunity for learning and change within the workplace. Journal of Interprofessional Care. 2013; 27(6): 469-475. PMid:23789898 https://doi.org/10.3109/13561820.2013. 805735

[58] Salas E, Rosen, MA. Building high reliability teams: progress and some reflections on teamwork training. Quality and Safety in Health Care. 2013; 22: 369-373.

[59] Scotten M, Manos EL, Malicoat A, et al. Minding the gap: Interprofessional communication during inpatient and post discharge chasm care. Patient Education and Counseling. 2015; 98: 895900. PMid:25862470 https://doi.org/10.1016/j.pec. 2015 .03 .009

[60] Reeves S. Ideas for the development of the interprofessional field. Journal of Interprofessional Care. 2010; 24(3): 217-219. PMid:20388025 https://doi.org/10.3109/13561821003788 930

[61] Weingart LR, Cronin MA. Teams research in the 21st Century: A case for theory consolidation. In E. Salas, G. F. Goodwin, \& C.S. Shawn
(Eds.), Team Effectiveness in Complex Organizations. Psychology Press, New York, NY. 2009; 509-524.

[62] Institute of Medicine. Measuring the impact of interprofessional education on collaborative practice and patient outcomes. The National Academies Press, Washington, DC. 2015.

[63] Gullette, ECD. Team coaching. In D.D. Riddle, E.R. Hoole, \& E.C.D. Gullette (Eds.), The center for creative leadership: Handbook of coaching in organizations. Jossey-Bass, San Francisco, CA. 2015.

[64] Cannon-Bowers JA, Salas E, Converse S. Shared mental models in expert decision making. In N.J.J. Castellan (Ed.), Individual and group decision making. L. Erlbaum Associates, Hillsdale, NJ. 1993.

[65] Hirschfield RR, Jordan MH. Becoming team players: Team members' mastery of teamwork knowledge as a predictor of team task proficiency and observed teamwork effectiveness. Journal of Applied Psychology. 2006; 91(2): 467-474. PMid:16551197 https: //doi.org/10.1037/0021-9010.91.2.467

[66] Stevens MJ, Campion MA. The knowledge, skill, and ability requirements for teamwork: implications for human resource management. Journal of Management. 1994; 20(2): 503-530. https: //doi.org/10.1177/014920639402000210

[67] Kozlowski SWJ, Gully SM, McHugh PP, et al. A dynamic theory of leadership and team effectiveness: Developmental and task contingent leader roles. Research in Personnel and Human Resources Management. 1996; 14: 253-305.

[68] Senge PM. The fifth discipline: The art and practice of the learning organization. Doubleday, NY. 1990.

[69] Covey SR. The seven habits of highly effective people. Simon and Schuster, Inc., New York. 1989.

[70] Gottman JM. What predicts divorce? Erlbaum, Hillsdale, NJ. 1994.

[71] Beach MC, Inui T. Relationship-centered care research network Relationship-centered care: A constructive reframing. Journal of General Internal Medicine. 2006; 24(Suppl. 1): 3-8. 